\title{
Editorial
}

\section{Tobacco smoking prevention and control in Canada: where do we go from here?}

\author{
Thierry Gagné, PhD (1); Jennifer L. O’Loughlin, PhD (2,3)
}

Despite steady declines in the past 30 years, with a record low prevalence of $15 \%$ in 2019 , tobacco smoking continues be a leading public health burden in Canada, especially in socially disadvantaged groups. ${ }^{1}$ New and unforeseen tobaccorelated issues continue to emerge that threaten these declines and challenge our understanding of tobacco use. Rapid uptake of vaping among youth, unanticipated effects of new legislation (e.g. cannabis) on tobacco smoking, evolving evidence on the distribution of vaping and its relationship with smoking initiation and cessation, and the effects of the COVID-19 pandemic on tobacco use are, among others, critical issues that will drive tobacco control research and policy agendas into the future.

In partnership with Health Promotion and Chronic Disease Prevention in Canada: Research, Policy and Practice (the HPCDP Journal), we stewarded a special issue on tobacco and vaping prevention and control in Canada, calling for new evidence on policy gaps and implementation challenges, inequalities in tobacco and vaping use and associations among use of vaping products, smoking cessation and harm reduction behaviours in smokers.

We received 20 submissions from tobacco and vaping control advocates and researchers in Canada, which, after peer review, resulted in 10 that would go to publication. Although the majority of submissions addressed vaping, the number and scope of accepted manuscripts prompted us to publish two issues. This first issue focusses, for the most part, on cutting-edge issues related to tobacco smoking and the upcoming issue will spotlight vaping. In the current issue, we present two commentaries-one led by Hagen ${ }^{2}$ and one by Melamed $^{3}$ - that challenge the past five years of tobacco control and question the complex role of the COVID-19 pandemic in future tobacco control efforts. In one of two original research papers, Pelekanakis et al. ${ }^{4}$ delve into the reasons underpinning continued provincial differences in smoking prevalence. In the second, Williams et al. ${ }^{5}$ identify predictors of e-cigarette uptake among high school students in Canada. Finally, an "At-a-glance” report by Worrell and Hagen ${ }^{6}$ offers new estimates of cigarette affordability across provinces over time.

Each paper sheds new light on current core issues related to Canadian capacity to support declines in smoking prevalence. First, Hagen ${ }^{2}$ reminds us that current obstacles include both the hesitation of provincial and federal governments to continue championing tobacco control as a priority, and their consequent failure to redirect sufficient funds towards bold new action. The Pelekanakis ${ }^{4}$ study asked which proximal contributor is most relevant to smoking prevalence and found that youth initiation likely drives differences in prevalence between Quebec and other provinces. The authors argue that addressing initiation therefore represents a key target to support continued declines in smoking prevalence, at least in Quebec.

Cigarette affordability and vaping have been associated with youth initiation, ${ }^{7,8}$ and findings by both Worrell and Hagen ${ }^{6}$ and Williams et al. ${ }^{5}$ offer insights to this end.

Worrell and Hagen ${ }^{6}$ highlight that cigarette affordability cannot be gleaned from tax rates alone because the effects of taxation on consumption depends on purchasing capacity (e.g. using WHO standards, the authors calculated that the CAD 10.90 increase in Prince Edward Island and the CAD 15.00 increase in Alberta in excise tax rates per 200 cigarettes between 2009 and 2019 were associated with the same increases in relative affordability). To ensure meaningful change, new tax increases must take this into account. Importantly, strong taxation strategies are likely to have a positive impact on reducing socioeconomic inequalities in smoking initiation. ${ }^{9}$

Reminding us of the significance of inequalities in smoking initiation, Williams et al. ${ }^{5}$ report that vaping initiation among high school students is more common among adolescents who skip school, perform less well academically and who have trouble with emotional coping-supporting that vaping may also represent a new mechanism by which vulnerable youth are more likely to initiate tobacco smoking, thereby perpetuating social inequalities.

Continuing on this theme, the Melamed $^{3}$ commentary highlights that inequalities in smoking must be a critical research focus as society emerges from the COVID-19 pandemic. Pandemic-related lockdowns altered numerous circumstances that influence smoking behaviour, including the environments in which smokers spend time, their financial security and their

\footnotetext{
Author references:

1. Research Department of Epidemiology and Public Health, University College London, London, United Kingdom

2. Centre de recherche du Centre hospitalier de l'Université de Montréal, Montréal, Quebec, Canada

3. Département de médecine sociale et préventive, École de santé publique de l'Université de Montréal, Montréal, Quebec, Canada

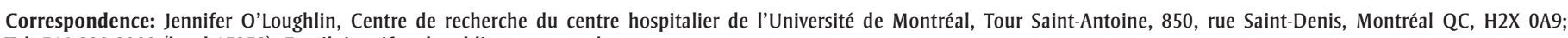
Tel: 514-890-8000 (local 15858); Email: jennifer.oloughlin@umontreal.ca
} 
capacity to cope with distress and boredom. The first year of the pandemic resulted in a bevy of fast-tracked scientific papers, often with weak evidence. We now need robust, high-quality evidence to better understand how COVID-19 has affected smokers' behaviour and whether these changes will influence initiation and cessation after the pandemic.

Despite the ongoing, immense public health burden of tobacco use, only a small number of researchers in Canada are engaged in population-based tobacco research. In the early 2000s, the Canadian Tobacco Control Research Initiative (CTCRI) represented a creative and bold endeavour that aimed to build a collaborative tobacco control research community in Canada, facilitate new leadership, support young researchers that could sustain this community and provide "protected" funding for high-quality, high-impact tobacco research. ${ }^{10}$ The organization was dismantled in 2009 after approximately 10 years, on the premise that it had attained these objectives, that the tobacco problem was "solved" and that Canada needed to move on to new, more pressing public health issues such as obesity.

It is our contention that, while the CTCRI initiative may have sown the seeds to achieve its objectives, its promise has fallen short in the ensuing years. Populationbased tobacco research in Canada is now undertaken by a handful of disconnected research teams, and the number of new, highly trained tobacco control researchers emerging from within these teams will not suffice to carry the torch. We believe that Canadian research capacity in tobacco control needs a critical boost into the next decade to support relevant cutting-edge research that deeply probes and can usefully inform the analysis of the complex and emerging issues highlighted in this issue of the HPCDP Journal and beyond. Canada must attract the next generation of well-trained researchers with well-honed methodological skills to lead Canada toward a tobacco endgame.

As guest editors, we thank our contributors (and peer reviewers) for providing content that calls for renewed attention to the longstanding public health problem of tobacco use. In conjunction with other tobacco-related position statements recently released in Canada, ${ }^{11}$ we hope that these special issues inspire reflection in Canada on past successes in tobacco control, in recognition that the battle is far from over as new and even more challenging issues emerge, and in acceptance that renewed commitment is needed to maintain and build Canadian capacity in tobacco control research.

Research priorities include assuring that the interventions that have supported the decline in smoking prevalence up to 2020 continue to be relevant and effective, and discovering whether vaping will contribute to a next generation of youth grappling with nicotine addiction. Also, top on our research agenda is the need for deeper, evidence-based understanding of the impact of COVID-19 on tobacco use, particularly in vulnerable subgroups, and of gaps in programs and policy that perpetuate social inequalities in smoking. We particularly hope that renewed attention to tobacco control research will help practitioners and policy makers anticipate and better prepare for the inevitable new challenges that will continue to emerge until a tobacco endgame is fully realized.

\section{Acknowledgements}

TG is funded by fellowship awards from the Canadian Institutes of Health Research (CIHR) and Fonds de recherche du QuébecSanté (FRQS). JOL held a Tier 1 Canada Research Chair in the Early Determinants of Adult Chronic Disease 2006-21. The authors thank Cynthia Callard for her feedback during the writing of the editorial.

\section{Conflicts of interest}

The authors declare no competing interests.

\section{Statement}

The content and views expressed in this article are those of the authors and do not necessarily reflect those of the Government of Canada.

\section{References}

1. Statistics Canada. Health fact sheets: smoking, 2019 [Internet]. Ottawa (ON): Statistics Canada; 2020 [cited 2021 Jul 1]. Available from: https://www 150 .statcan.gc.ca/n1/pub/82-625-x/2020001 /article/00003-eng.htm

2. Hagen L, Schwartz R. Is "less than 5 by 35 " still achievable? Health Promot Chronic Dis Prev Can. 2021;41(10): 288-91. https://doi.org/10.24095/hpcdp .41 .10 .03
3. Melamed OC, Zawertailo L, Schwartz R, Buckley L, Selby P. Protecting vulnerable groups from tobacco-related harm during and following the COVID19 pandemic. Health Promot Chronic Dis Prev Can. 2021;41(10):282-7. https:// doi.org/10.24095/hpcdp.41.10.02

4. Pelekanakis A, O’Loughlin JL, Gagné T, Callard C, Frohlich KL. Initiation or cessation: what keeps the prevalence of smoking higher in Quebec than in the rest of Canada? Health Promot Chronic Dis Prev Can. 2021;41(10): 306-14. https://doi.org/10.24095/hpcdp .41 .10 .05

5. Williams GC, Cole AG, de Groh M, Jiang Y, Leatherdale ST. Investigating individual-level correlates of e-cigarette initiation among a large sample of Canadian high school students. Health Promot Chronic Dis Prev Can. 2021; 41(10):292-305. https://doi.org/10 .24095/hpcdp.41.10.04

6. Worrell M, Hagen L. Cigarette affordability in Canadian provinces: a 10-year review. Health Promot Chronic Dis Prev Can. 2021;41(10):315-8. https://doi.org/10.24095/hpcdp.41 .10 .06

7. Bader P, Boisclair D, Ferrence R. Effects of tobacco taxation and pricing on smoking behavior in high risk populations: a knowledge synthesis. Int J Environ Res Public Health. 2011; 8(11):4118-39. https://doi.org/10.3390 /ijerph8114118

8. Khouja JN, Suddell SF, Peters SE, Taylor AE, Munafò MR. Is e-cigarette use in non-smoking young adults associated with later smoking? A systematic review and meta-analysis. Tob Control. 2020;30(1):8-15. https://doi .org/10.1136/tobaccocontrol-2019 $-055433$

9. Hill S, Amos A, Clifford D, Platt S. Impact of tobacco control interventions on socioeconomic inequalities in smoking: review of the evidence. Tob Control. 2014;23(e2):e89-e97. https:// doi.org/10.1136/tobaccocontrol-2013 $-051110$ 
10. Riley BL, Viehbeck SM, Cohen JE, Chia MC. "The magic is in the mix": lessons from research capacity building in the Canadian tobacco control community, 2000-2010. Can J Public Health. 2013;104(2):e173-e176. https:// doi.org/10.1007/BF03405684

11. Canadian Public Health Association (CPHA). Tobacco and vaping use in Canada: moving forward [Internet]. Ottawa (ON): CPHA; 2021 [cited 2021 Jul 1]. Available from: https://www .cpha.ca/tobacco-and-vaping-use -canada-moving-forward 